\title{
Níveis de desfolha na fase reprodutiva da soja, cv. Ocepar 14, sobre dois sistemas de cultivo ${ }^{1}$
}

\author{
Defoliation levels during reproductive stages of soybean cv. Ocepar 14, under \\ two tillage systems
}

\section{Marcus Antônio Gonçalves Costa ${ }^{1}$ Ricardo Silveiro Balardin ${ }^{2}$ Ervandil Correa Costa ${ }^{3}$ Anderson Dionei Grützmacher ${ }^{4}$ Mauro Tadeu Braga da Silva ${ }^{5}$}

\section{RESUMO}

\begin{abstract}
Este estudo teve como objetivo avaliar níveis de desfolha efetuados nos estádios reprodutivos da cultivar de soja Ocepar 14, nos sistemas de plantio direto e convencional. Dois experimentos foram conduzidos na Universidade Federal de Santa Maria, em Santa Maria, RS, no ano agrícola 1998/99, no sistema $D B C$, com 4 repetições e simulação de níveis de desfolha de 33, 67 e 100\%, além da testemunha sem desfolha. A desfolha de $100 \%$ promoveu redução significativa do rendimento de grãos, nos estádios $R 3, R 4, R 5$ e R6, tanto no plantio direto quanto no convencional. Os estádios mais afetados pela desfolha total foram $R 4$ no plantio direto e R4 e R5 no plantio convencional. Desfolhas de 33 e 67\% somente reduziram significativamente o rendimento de grãos quando aplicados em R3 no sistema de plantio direto. No plantio convencional, desfolha de 33\% não causou decréscimo no rendimento de grãos em nenhum dos estádios avaliados, enquanto a desfolha de $67 \%$ provocou decréscimo significativo no rendimento de grãos no estádio $R 5$. A redução percentual no rendimento de grãos induzida pela desfolha não diferiu entre os sistemas de preparo do solo, em nenhum dos niveis de desfolha empregados.
\end{abstract}

Palavras-chave: Glycine max, plantas danificadas, plantio direto, plantio convencional.

\section{ABSTRACT}

This study aimed to evaluate the defoliation levels under reproductive stages, of soybean $\mathrm{cv}$. Ocepar 14, over no- tillage and conventional tillage systems. Two experiments were conducted, during the 1998/99 growing season, in Santa Maria, in the State of Rio Grande do Sul, Brazil. The defoliation levels were 0, 33, 67 and 100\%. Total defoliation decreased grain yield significantly when performed at $R 3, R 4$, $R 5$ and R6 stages in both no-tillage and conventional tillage. Total defoliation was more prejudicial to yield at $R 4$ in notillage, while R4 and R5 were more sensitive to full in conventional tillage. Defoliations of 33 and $67 \%$ decreased grain yield only when applied at R3 stage in the no-tillage system. In the conventional tillage, only defoliation of $67 \%$ caused significant reductions on yield in $R 5$ stage. There was no difference between soil tillage systems in the percentage of yield reduction promoted by any of the evaluated defoliation levels.

Key words: Glycine max, damaged plants, no-tillage, conventional tillage.

\section{INTRODUÇÃO}

A importância da cultura da soja no Brasil pode ser verificada através da expansão da área e produção de grãos, com 13,60 milhões de hectares, produção de 32,57 toneladas e rendimento de grãos de $2.399 \mathrm{~kg} \mathrm{ha}^{-1}$, sendo responsável pela movimentação de U\$ 5 a 7,5 bilhões, além de estimular outros setores da

${ }^{1}$ Parte da Dissertação de Mestrado apresentada pelo primeiro autor ao Curso de Pós-graduação em Agronomia, Universidade Federal de Santa Maria (UFSM), em fevereiro de 2001. Apoio: bolsa de estudos da CAPES.

${ }^{2}$ Engenheiro Agrônomo, MSc, Doutorando do Curso de Pós-graduação em Fitossanidade, Bolsista do CNPq FAEM/UFPel, Pelotas, RS. Email: marcusgc@ufpel.tche.br Autor para correspondência..

${ }^{3}$ Engenheiro Agrônomo, Doutor, Professor do Departamento de Defesa Fitossanitária, Centro de Ciências Rurais, UFSM, Campus Universitário, Prédio 42, 97105-900, Santa Maria-RS. Pesquisador do CNPq.

${ }^{4}$ Engenheiro Agrônomo, Doutor, Professor do Departamento de Fitossanidade, FAEM/UFPel, CP 354, 96010-900, Pelotas-RS. Pesquisador do CNPq.

${ }^{5}$ Engenheiro Agrônomo, MSc, Doutorando do Curso de Pós-Graduação em Agronomia, CCR, UFSM. Pesquisador da FUNDACEP. 
cadeia produtiva (IBGE, 2000; ANUÁRIO BRASILEIRO DE SOJA, 2000).

A área cultivada com soja no sistema de plantio direto cresceu significativamente, principalmente na região Sul da Brasil, durante a década de 90 , reduzindo a erosão, diminuindo o custo de produção, aumentando a matéria orgânica do solo, elevando a fertilidade e incrementando a diversidade de seres vivos (FERNANDES, 1997).

GAZZONI (1974) cita que reação da planta de soja à desfolha artificial é muito semelhante à reação causada pelos insetos filófagos, auxiliando a pesquisa a determinar níveis de dano econômico que racionalizarão o uso de inseticidas no manejo integrado de insetos-praga. Vários trabalhos com desfolha em soja foram realizados para simular o dano de lagartas desfolhadoras, sendo que grande parte deles foram conduzidos no sistema de plantio convencional. No Brasil, a maioria dos trabalhos foram realizados com cultivares atualmente não mais utilizadas, como é o caso da UFV-10, Santa Rosa e Paraná (GAZZONI, 1974; SALVADORI \& CORSEUIL, 1979; PISSAIA \& COSTA, 1981; DIOGO et al., 1997; GAZZONI \& MOSCARDI, 1998; PAIM, 1999; RIBEIRO \& COSTA, 2000 e REICHERT, 2001). No exterior, os trabalhos foram feitos com cultivares diferentes das utilizadas no Brasil, como, por exemplo, a Richland, Jackson, Hampton, Bragg, Hardee, Jew 46, Lee 74, Beeson, Braxton, Foster, Duocrop e Centennial. (WEBER, 1955; STONE \& PEDIGO, 1972; TURNIPSEED, 1972; CAVINESS \& THOMAS, 1980; FEHR et al., 1981; GOLI \& WEAVER, 1986; BOARD et al., 1994). Estes trabalhos dão suporte às recomendações para a cultura da soja, indicando que o controle com inseticidas deve ser realizado com $30 \%$ de desfolha ou 40 lagartas grandes $(>1,5 \mathrm{~cm}$ de comprimento por pano de batida) no período vegetativo, e $15 \%$ de desfolha ou 40 lagartas grandes, no período reprodutivo (REUNIÃO DE PESQUISA DE SOJA DA REGIÃO SUL, 2001).

Considerando que há poucos trabalhos com desfolha em soja que utilizam cultivares registradas para cultivo atualmente e conduzidos no sistema de plantio direto, realizou-se esta pesquisa. Seus objetivos foram avaliar o efeito de níveis de desfolha artificial em diferentes estádios reprodutivos da cultivar Ocepar 14, nos sistemas de plantio direto e convencional, e confirmar se os níveis de ação preconizados para o controle de lagartas desfolhadoras são adequados para esta cultivar.

\section{MATERIAL E MÉTODOS}

O estudo foi desenvolvido em Santa Maria, RS, no ano agrícola de 1998/99, em área experimental do Departamento de Defesa Fitossanitária da Universidade Federal de Santa Maria.

Foram conduzidos dois experimentos: um no sistema convencional e outro no sistema de plantio direto. O preparo do solo, para o sistema convencional, foi realizado com arado e grade, no mês de novembro, um dia antes da semeadura. No sistema de plantio direto (estabelecido desde 1995), efetuou-se a dessecação da vegetação existente (aveia e azevém), uma semana antes da semeadura. A semeadura da soja cv. Ocepar 14 foi feita mecanicamente, em ambos os sistemas de cultivo, numa densidade de 22 sementes $\mathrm{m}^{-1} \mathrm{e}$ espaçamento entre linhas de $0,47 \mathrm{~m}$, em 10 de novembro de 1998.

$\mathrm{O}$ delineamento experimental foi o de blocos ao acaso, com quatro repetições, sendo as unidades experimentais constituídas de 5 linhas por $2,50 \mathrm{~m}$ de comprimento. A área útil de cada unidade amostral constituiu-se das três linhas centrais com $1,50 \mathrm{~m}$ de comprimento, totalizando $2,11 \mathrm{~m}^{2}$.

Cada experimento constou de 16 tratamentos, resultantes da combinação de 4 níveis de desfolha e 5 estádios de desenvolvimento da cultura. Os níveis de desfolha foram obtidos pela retirada, com tesoura, de um folíolo, dois folíolos, tomados ao acaso e todos os folíolos de todas as folhas trifolioladas da planta, alcançando os valores de 33, 67 e 100\%, respectivamente. O nível de $0 \%$ representou a testemunha. Os níveis de desfolha foram aplicados numa única operação, nos estádios R2, R3, R4, R5 e R6 da escala de FEHR et al. (1971).

Para avaliação do rendimento de grãos, colheu-se a produção das plantas da área útil, sendo corrigido a umidade das sementes para $13 \%$.

Os dados obtidos foram submetidos à análise de variância para verificar a significância da interação entre os níveis de desfolha e os estádios de desenvolvimento, bem como os efeitos individuais de cada fator. O Teste de Duncan foi utilizado para a comparação das médias, em nível de significância de 5\%. A análise de regressão, entre médias, foi testada nos modelos linear, quadrático e cúbico. Foi utilizado o Teste t, nos sistemas de cultivo para a comparação entre duas médias com variâncias populacionais desconhecidas $(\mathrm{a}=5 \%)$.

\section{RESULTADOS E DISCUSSÃO}

Em R2, no sistema de plantio direto, o rendimento de grãos foi menor em relação à 
testemunha somente quando aplicado no nível $100 \%$ de desfolha (Tabela 1), concordando com CAVINESS \& THOMAS (1980), PISSAIA et al. (1982) e DIOGO et al. (1997). Por outro lado, no sistema de plantio convencional, a desfolha em R2 não causou decréscimo significativo ao rendimento de grãos em qualquer nível de desfolha, confirmando os resultados de PISSAIA \& COSTA (1981) e GAZZONI \& MOSCARDI (1998). Desfolhas aplicadas no florescimento não exercem influência significativa sobre rendimento de grãos, devido à capacidade de recuperação da planta de soja a danos foliares (SALVADORI \& CORSEUIL, 1979).

No estádio R3, todos os níveis de desfolha causaram reduções significativas no rendimento de grãos em relação à testemunha no sistema de plantio direto. As reduções foram de aproximadamente 23, 26 e $70 \%$ para os níveis de desfolha de 33, 67 e 100\%, respectivamente (Tabela 1). No sistema convencional, apenas o nível de desfolha de $100 \%$ reduziu significativamente o rendimento de grãos, com decréscimo de aproximadamente $60 \%$ em relação à testemunha. Os níveis de 33 e $67 \%$ provocaram decréscimos percentuais no rendimento de grãos de 5 e $25 \%$, respectivamente. Estes resultados concordam com aqueles obtidos por GAZZONI (1974) e FEHR et al. (1977) e contrariam aos de SALVADORI \& CORSEUIL (1979). O estádio R3 é apontado como um dos mais críticos às plantas de soja, para recuperar danos na sua área foliar (TURNIPSEED, 1972;
GAZZONI, 1974; SALVADORI \& CORSEUIL, 1979; PAIM, 1999; RIBEIRO \& COSTA, 2000). Para SHIBLES et al. (1975), a desfolha altera a relação fonte/dreno, fazendo com que a planta passe por um rearranjo das funções fisiológicas. PISSAIA et al. (1982) mencionam que níveis de desfolha causam na planta competição entre partes reprodutivas e vegetativas. A formação de novas folhas ocorre às expensas de carboidratos que iriam ser empregados na formação dos legumes. Esta competição é mais acentuada a medida em que os níveis de desfolha aumentam, ocasionando maiores reduções ao rendimento de grãos.

Para o estádio R4, somente a desfolha de $100 \%$ promoveu redução significativa no rendimento de grãos em relação à testemunha, com decréscimos de $82 \%$ no plantio convencional e $84 \%$ no plantio direto (Tabela 1). Este resultado discorda de CAVINESS \& THOMAS (1980), PISSAIA et al. (1982) e DIOGO et al. (1997), os quais observaram que este estádio foi o mais afetado pelas desfolhas de $33 \%, 67 \%$ e $100 \%$, destacando que a falta de folhas diminui o fornecimento de carboidratos, que tanto os caules como os pecíolos são incapazes de suprir a sua demanda para os legumes e grãos em desenvolvimento. No presente trabalho, é possível que a retirada de $33 \%$ e $67 \%$ das folhas não tenha propiciado queda significativa ao rendimento de grãos devido ao hábito de crescimento semi-determinado desta cultivar e, assim, com maior capacidade da planta em emitir

Tabela 1 - Rendimento de grãos $\left(\mathrm{kg} \mathrm{ha}^{-1}\right)$ da cultivar Ocepar 14, submetida a desfolha em diferentes estádios reprodutivos de desenvolvimento, sob dois sistemas de cultivo. Santa Maria, RS, 2002.

\begin{tabular}{|c|c|c|c|c|c|c|}
\hline \multirow{3}{*}{ Desfolha-mento (\%) ${ }^{1 /}$} & \multicolumn{6}{|c|}{ Plantio Direto } \\
\hline & \multicolumn{6}{|c|}{ Estádios $^{2 /}$} \\
\hline & $\mathbf{R 2}$ & R3 & R4 & R5 & R6 & C.V. (\%) \\
\hline $\mathbf{0}$ & $3763 \mathbf{a}$ & $3763 \mathbf{a}$ & $3763 \mathbf{a}$ & $3763 \mathbf{a}$ & $3763 \mathbf{a}$ & - \\
\hline 33 & $3179 \mathbf{a b} \mathbf{A}$ & 2910 b A & 3653 a A & 3363 a A & $3700 \mathbf{a} \mathbf{A}$ & 23,36 \\
\hline 67 & $3282 \mathbf{a b ~ A}$ & 2792 bc A & 2870 a A & 3034 a A & 3063 a A & 13,77 \\
\hline 100 & 2369 b A & $1130 \mathrm{~d} C$ & 589 b D & 1098 b C & 1819 b B & 17,80 \\
\hline \multirow[t]{2}{*}{ C.V. (\%) } & 29,46 & 15,58 & 28,20 & 25,33 & 21,24 & \\
\hline & \multicolumn{6}{|c|}{ Plantio Convencional } \\
\hline $\mathbf{0}$ & $3195 \mathbf{a}$ & $3195 \mathbf{a}$ & $3195 \mathbf{a}$ & $3195 \mathbf{a}$ & $3195 \mathbf{a}$ & - \\
\hline 33 & 3259 a A & 3041 a A & 3121 a A & 3098 a A & 3020 a A & 14,34 \\
\hline 67 & 3239 a A & 2380 a B & $2987 \mathbf{a} \mathbf{A B}$ & $2526 \mathbf{b} \mathbf{A B}$ & 2679 a AB & 16,77 \\
\hline 100 & 2763 a A & 1285 b B & 585 b D & 832 c CD & 1095 b BC & 26,77 \\
\hline C.V. (\%) & 14,29 & 22,11 & 10,65 & 12,14 & 18,51 & \\
\hline
\end{tabular}

${ }^{1 /}$ As médias não seguidas da mesma letra, minúscula nas colunas e maiúscula nas linhas, diferem estatisticamente pelo teste de Duncan em nível de $5 \%$ de probabilidade de erro.

${ }^{2 /}$ Estádios fenológicos de acordo com a escala de FEHR et al. (1971). 
novas folhas, contribuindo para uma maior competição por fotoassimilados.

No sistema de plantio direto, a remoção foliar em R5 causou efeito negativo somente no nível $100 \%$ de desfolha, provocando um decréscimo significativo de $71 \%$ no rendimento de grãos (Tabela 1). Em plantio convencional, os níveis de 67 e $100 \%$ de desfolha diferiram entre si e da testemunha com decréscimos significativos de $21 \mathrm{e}$ $74 \%$, respectivamente. A ausência de redução significativa ao rendimento com $33 \%$ de desfolha no sistema convencional pode ser atribuído ao maior acúmulo de matéria seca nas plantas. PISSAIA et al. (1982) verificaram menores perdas de matéria seca do caule e pecíolos, neste nível e neste estádio, compensando assim maiores acúmulos nos grãos e legumes a partir desta mesma época. Muitos autores relatam ser este estádio um dos mais afetados pela desfolha (TURNIPSEED, 1972; GAZZONI, 1974; SALVADORI \& CORSEUIL, 1979; PAIM, 1999 e RIBEIRO \& COSTA, 2000). Neste estádio, a cv. Ocepar 14 mostrou-se mais suscetível a desfolha no sistema de plantio convencional, principalmente pela redução no rendimento de grãos no nível de $67 \%$ de desfolha, enquanto que no sistema de plantio direto esse nível não exerceu influência significativa. Com a desfolha de $100 \%$ em R5, em ambos os sistemas de cultivo, a quantidade de reservas foi insuficiente para suprir a crescente demanda das estruturas reprodutivas e manter as estruturas vegetativas da planta, causando decréscimo significativo ao rendimento de grãos. Assim, as reservas acumuladas no caule, pecíolos e legumes das plantas ficaram limitadas, sendo insuficientes para suprir a demanda dos grãos (TURNIPSEED, 1972; PISSAIA \& COSTA, 1981; PISSAIA et al., 1982 e SHIBLES et al., 1975).

Verificou-se no estádio R6, nos dois sistemas de cultivo, que a retirada de $100 \%$ das folhas propiciou decréscimo significativo ao rendimento de grãos quando comparado à testemunha (Tabela 1). Entretanto, a total remoção das folhas foi menos prejudicial em R6 do que nos estádios R3, R4 e R5. Esses resultados confirmam aqueles obtidos por FEHR et al. (1981), PISSAIA \& COSTA (1981), GOLI \& WEAVER (1986) e BOARD et al. (1994), os quais concluíram que a desfolha total causou decréscimo significativo no rendimento de grãos. Concordam em parte com GAZZONI \& MOSCARDI (1998) e RIBEIRO \& COSTA (2000), os quais relataram que desfolhas de $67 \%$ e $100 \%$ reduziram significativamente o rendimento de grãos, sendo que os primeiros autores usaram a cv. Paraná e os segundos a cv. BR 16. Contrariam, porém, os resultados de
SALVADORI \& CORSEUIL (1979) que ao removerem $67 \%$ das folhas da cv. Santa Rosa encontraram redução significativa no rendimento de grãos, e PAIM (1999) que ao retirar as folhas da cv. FT Abyara não encontrou redução significativa no rendimento de grãos entre todos os níveis de desfolha testados.

A remoção de $100 \%$ das folhas causou diferença significativa nos estádios R3, R4, R5 e R6, em relação ao estádio $\mathrm{R} 2$, com decréscimos no rendimento de grãos de aproximadamente 52, 75, 54 e $23 \%$, respectivamente, tanto no plantio direto quanto no convencional (Tabela 1). Esses resultados estão de acordo com aqueles obtidos por STONE \& PEDIGO (1972), evidenciando que a planta de soja apresenta menor redução no rendimento de grãos quando a desfolha é aplicada nos estádios reprodutivos mais avançados, no caso R6, em conseqüência da planta apresentar menor quantidade de folhas.

Com relação aos sistemas de cultivo empregados, observa-se que não houve diferença significativa na percentagem de decréscimo no rendimento de grãos imposta pelos diferentes níveis de desfolha (Tabela 2). Também se nota que a medida em que se elevam os níveis de desfolha, o rendimento de grãos decresce em cada sistema de plantio, concordando com TURNIPSEED (1972), SALVADORI \& CORSEUIL (1979), PAIM (1999), RIBEIRO \& COSTA (2000) e REICHERT (2001).

A regressão quadrática expressou o melhor ajuste dos dados para níveis de desfolha e os coeficientes de determinação foram significativos em cada estádio, no plantio direto (Figuras 1a, b, c, d, e) e no plantio convencional (Figuras 1f, g, h, i, j). Esses resultados demonstraram alta relação entre o rendimento de grãos e os níveis de desfolha. No plantio direto, as desfolhas propiciaram queda no rendimento de grãos, especialmente em R3, R4 e R5 onde decresceu à medida que aumentou o nível de desfolha.

Tabela 2 - Percentagem de redução (\%) no rendimento de grãos da cultivar Ocepar 14, submetida a desfolhas de 33, 67 e 100\%, nos estádios R2, R3, R4, R5 e R6, sob dois sistemas de cultivo. Santa Maria, RS, 2002.

\begin{tabular}{lccc}
\hline & \multicolumn{4}{c}{ Níveis de desfolhamento $(\mathbf{\%})^{\mathbf{1 /}}$} \\
Sistemas de cultivo & $\mathbf{3 3}$ & $\mathbf{6 7}$ & $\mathbf{1 0 0}$ \\
\hline Direto & $10,67 \mathbf{a}$ & $21,02 \mathbf{a}$ & $62,76 \mathbf{a}$ \\
Convencional & $2,72 \mathbf{a}$ & $13,52 \mathbf{a}$ & $58,94 \mathbf{a}$ \\
\hline
\end{tabular}

${ }^{1 /}$ As médias não seguidas de mesma letra nas colunas diferem estatisticamente entre si pelo Teste $\mathrm{t}$ em nível de $5 \%$ de probabilidade de erro. 


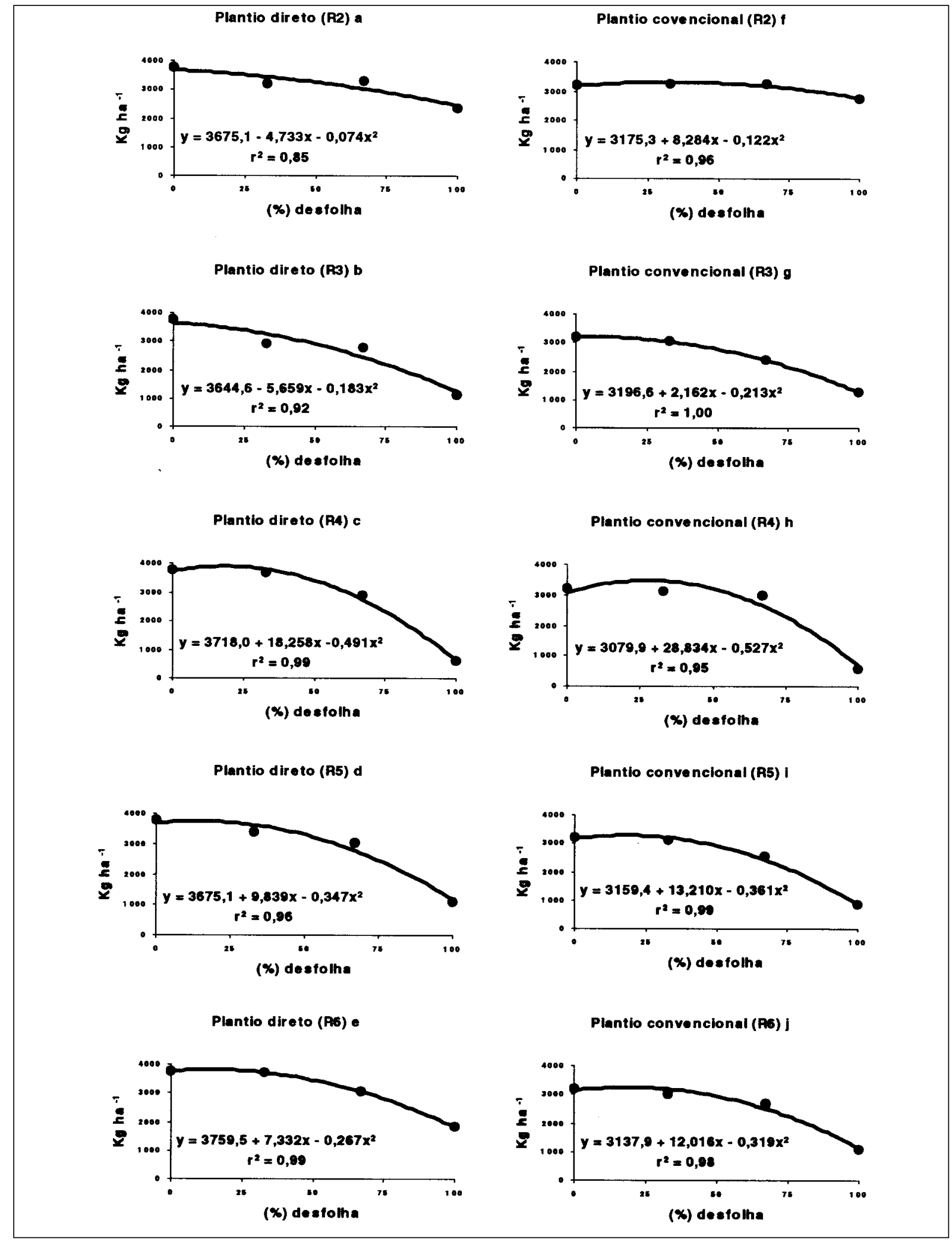

Figura 1 - Efeito da percentagem de desfolha sobre o rendimento de grãos da cultivar Ocepar 14, em diferentes subperíodos do desenvolvimento reprodutivo, sob plantio direto (a, b, c, d, e) e plantio convencional (f, g, h, i, j). Santa Maria, RS, 2002.

Ciência Rural, v. 33, n. 5, set-out, 2003. 
Os estádios R3 e R4 no nível de desfolha de $67 \%$ apresentaram maiores quedas. Quando se aplicou $100 \%$ de desfolha, todos os estádios sofreram decréscimos no rendimento de grãos, porém o estádio R4 foi o mais afetado, confirmando os resultados da análise da variância. No plantio convencional, à medida que aumentou o nível de desfolha decresceu o rendimento de grãos, exceto no estádio R2, em que somente no nível $100 \%$ de desfolha aconteceu queda do mesmo. Os estádios R4 e R5 foram os mais afetados, apresentando os maiores decréscimos, principalmente no nível $100 \%$ de desfolha.

São necessárias novas pesquisas com outras cultivares, porque este estudo indica que a cultivar Ocepar 14 é mais tolerante à redução de área foliar do que as cultivares usadas em pesquisas citadas anteriormente e, inclusive, cultivares antigas que serviram de embasamento para a recomendação oficial. Também REICHERT (2001) cita que as cultivares CD 203 e BRS 66 são mais tolerantes aos desfolhamentos contínuos e seqüenciais do que a BRS 137. Além disso, esses estudos devem ser feitos com todas as cultivares registradas e as novas cultivares já devem ter estas informações no momento do seu registro.

\section{CONCLUSÕES}

Nas condições em que foi conduzido o presente estudo, pode-se concluir que as plantas da cultivar Ocepar 14, cultivadas tanto no plantio direto quanto no convencional, recuperam-se com grande facilidade aos danos causados a sua área foliar, na fase reprodutiva, confirmando com segurança o nível de ação recomendado no programa de manejo de lagartas desfolhadoras na cultura da soja.

\section{REFERÊNCIAS BIBLIOGRÁFICAS}

ANUÁRIO BRASILEIRO DE SOJA, 1. Passo Fundo: O Nacional, 2000. 143p.

BOARD, J.E.; WIER, A.T.; BOETHEL, D.J. Soybean yield reductions caused by defoliation during mid to late seed filling. Agronomy Journal, Madison, v.86, n.6, p.1074-1097, 1994.

CAVINESS, C.E.; THOMAS, J.D. Yield reduction from defoliation of irrigated and non-irrigated soybeans. Agronomy Journal, Madison, v.72, n.6, p.977-980, 1980.

DIOGO, A.M. et al. Influência da remoção de folhas, em vários estádios de desenvolvimento, na produção de grãos e em outras características agronômicas da soja (Glycine $\max$ (L.) Merril). Revista Ceres, Viçosa, v.44, n.253, p.272-285, 1997.
FEHR, W.R. et al. Stage of development descriptions for soybeans, Glycine $\max$ (L.) Merrill. Crop Science, Madison, v.11, n.6, p.929-931, 1971.

FEHR, W.R.; CAVINESS, C.E.; VORST, J.J. Response of Indeterminate and determinate soybean cultivars to defoliation and half-plant cut-off. Agronomy Journal, Madison, v.17, p.913917, 1977.

FEHR, W.R.; LAWRENCE, B.K.; THOMPSON, T.A. Critical stages of development for soybean defoliation. Crop Science, Madison, v.21, n.2, p.259-262, 1981.

FERNANDES, J.M.C. As doenças das plantas e o sistema de plantio direto. In: SEMINÁRIO INTERNACIONAL DO SISTEMA PLANTIO DIRETO, 2., Passo Fundo, 1997. Anais... Passo Fundo : Embrapa,CNPT, 1997. 310p. p.43-80.

GAZZONI, D.L. Avaliação de efeito de três níveis de desfolhamento aplicados em quatro estádios de crescimento de dois cultivares de soja (Glycine max (L.) Merrill), sobre a produção e a qualidade do grão. 1974. 70f. Dissertação (Mestrado em Fitotecnia) - Curso de Pós-graduação em Agronomia, Universidade Federal do Rio Grande do Sul.

GAZZONI, D.L.; MOSCARDI, F. Effect of defoliation levels on recovery of leaf area, on yield and agronomic traits of soybeans. Pesquisa Agropecuária Brasileira, Brasília, v.33, n.4, p.411424, 1998.

GOLI, A.; WEAVER, D.B. Defoliation responses of determinate and indeterminate late planted soybean. Crop Science, Madison, v.26, n.1, p.159-166, 1986.

PAIM, E.A. Efeitos do desfolhamento artificial em soja, sob plantio direto e convencional. 1999. 53f. Dissertação (Mestrado em Produção Vegetal) - Curso de Pós-graduação em Agronomia, Universidade Federal de Santa Maria.

PISSAIA, A.; COSTA, J.A. Influência de desfolhamentos artificiais sobre o rendimento de grãos e seus componentes, em duas cultivares de soja. Pesquisa Agropecuária Brasileira, Brasília, v.3, n.4, p.47-61, 1981.

PISSAIA, A.; COLASANTE, L.O.; COSTA, J.A. Efeitos de desfolhamentos artificiais sobre a produção e o acúmulo de matéria seca em duas cultivares de soja. Pesquisa Agropecuária Brasileira, Brasília, v.17, n.6, p.873-881, 1982.

REICHERT, J.L. Avaliação de desfolhamentos contínuos e seqüenciais, simulando dano de pragas, sobre as cultivares de soja BRS 137, CD 203 e BRS 66. 2001. 121f. Dissertação (Mestrado em Produção Vegetal) - Curso de Pós-graduação em Agronomia, Universidade Federal de Santa Maria.

REUNIÃO DE PESQUISA DE SOJA DA REGIÃO SUL, (29.: 2001: Porto Alegre). Indicações técnicas para a cultura da soja no Rio Grande do Sul e Santa Catarina 2001/2002. Porto Alegre : FEPAGRO, 2001. 138p.

RIBEIRO, A.L. de P.; COSTA, E.C. Desfolhamento em estádios de desenvolvimento da soja, cultivar BR16, no rendimento de grãos. Ciência Rural, Santa Maria, v.30, n.5, p.767-771, 2000 .

SALVADORI, J.R.; CORSEUIL, E. Efeito de quatro níveis de desfolha aplicadas em quatro estádios de desenvolvimento da soja 
(Glycine max (L.) Merrill), na produção de grãos. Agronomia Sulriograndense, Porto Alegre, v.15, n.1, p.91-101, 1979.

SHIBLES, R.M.; ANDERSON, I.C.; GIBSON, A.H. Soybean. In: EVANS, L.T. Crop phisiology: some case histories. London : Cambridge University, 1975. p.151-189.

STONE, J.D.; PEDIGO, L.P. Development and economic injury level of ten green cloverworm on soybean in Iowa.
Journal of Economic Entomology, College Park, v.65, n.1, p.197-201, 1972 .

TURNIPSEED, S.G Response of soybeans to foliage losses in South Carolina. Journal of Economic Entomology, College Park, v.65, n.1, p.224-229, 1972.

WEBER, C.R. Effect of defoliation and topping simulating hail injury to soybeans. Agronomy Journal, Madison, v.47, n.6, p.262-266, 1955. 